\title{
ASTER Data Analyses for Lithological Discrimination of Sittampundi Anorthositic Complex, Southern India
}

\author{
S. Arivazhagan ${ }^{1 *}$, S. Anbazhagan ${ }^{2}$ \\ ${ }^{1}$ Centre for Applied Geology, The Gandhigram Rural Institute - Deemed Univesity, \\ Dindigul - 624302, India \\ ${ }^{2}$ Centre for Geoinformatics and Planetary Studies, Periyar University, Salem - 636 011, India \\ Email: arivusv@gmail.com
}

\begin{abstract}
ASTER is an advanced Thermal Emission and Reflection Radiometer, a multispectral sensor, which measures reflected and emitted electromagnetic radiation of earth surface with 14 bands. The present study aims to delineate different rock types in the Sittampundi Anorthositic Complex (SAC), Tamil Nadu using Visible (VIS), near-infrared (NIR) and short wave infrared (SWIR) reflectance data of ASTER 9 band data. We used different band ratioing, band combinations in the VNIR and SWIR region for discriminating lithological boundaries. SAC is also considered as a lunar highland analog rock. Anorthosite is a plagioclase-rich igneous rock with subordinate amounts of pyroxenes, olivine and other minerals. A methodology has been applied to correct the cross talk effect and radiance to reflectance. Principal Component Analysis (PCA) has been realized on the 9 ASTER bands in order to reduce the redundancy information in highly correlated bands. PCA derived FCC results enable the validation and support to demarcate the different lithological boundaries defined on previous geological map. The image derived spectral profiles for anorthosite are compared with the ASTER resampled laboratory spectra, JHU spectral library spectra and Apollo 14 lunar anorthosites spectra. The Spectral Angle Mapping imaging spectroscopy technique has been practiced to classify the ASTER image of the study area and found that, the processing of ASTER remote sensing data set can be used as a powerful tool for mapping the terrestrial Anorthositic regions and similar kind of process could be applied to map the planetary surfaces (E.g. Moon).
\end{abstract}

Keywords: Anorthosites, ASTER, image processing, remote sensing.

\section{Introduction}

The Sittampundi Anorthosite Complex (SAC) is located in the Southern Peninsular India in Namakkal district of Tamil Nadu state. It lies between Northern latitude of $11^{0} 10^{\prime} 00$ " to $11^{0} 20^{\prime} 00$ " and Eastern longitude of $77^{0} 50^{\prime} 00^{\prime \prime}$ to $78^{\circ} 00^{\prime} 00^{\prime}$ (Figure. 1). The bounded area is mostly covered by layered anorthosites along with amphibolites, charnockites, hornblende biotite gneiss, pink migmatite and Tiruchengode granites. The Sittampundi Anorthositic Complex is one of the geological interested provinces, since it is bearing chromite (Ghosh and Konar, 2011) and also considered as occurrence of Platinum Group Elements (PGE) (Balaram, 2006). Beyond this, the mineralogy and the relative percentage of major oxides of Sittampundi anorthsoite is considered as an equivalent of lunar highland anorthositic rock (Anbazhagan and Arivazhagan 2010; Anbazhagan et al., 2012). Hence, the development of a suitable methodology to map and discriminate the different lithology in the anorthosite region, could be applicable to the remote sensing study of lunar surface.

Orbital remote sensing technology has great utility and progressed to advanced levels that are useful for lithological mapping, discrimination as well as identifying mineral deposits and production of geological maps at different scales (Abrams et al., 1983; Abrams and Hook, 1995; Sabins, 1997; Rowan and Mars, 2003; Rowan et al., 2006; Mars and Rowan, 2006; Gad and Kusky, 2007). Landsat satellite data have been utilized by several authors for lithologic discrimination (Sultan, et al., 1987; Davis and Berlin, 1987; Madani, 2002). In the recent years, several studies dealt with the utilization of ASTER images for lithologic discrimination and detection of alteration products (Gomez et al., 2005; Ninomiya and Cudahy, 2005; Pena and Abdelsalam, 2006; Qiu et al., 2006; Rowan et al., 2006; Gad and Kusky, 
2007). The VNIR, SWIR and TIR wavelength regions of ASTER data provide complementary data for lithologic discrimination and mapping of the alteration products (Qari et al., 2008).

The accessibility of inexpensive, satellite-borne, multispectral ASTER data has created new opportunities for the regional mapping of geological structure and rock types including alteration products, and regolith (Hewson et al., 2005). The TERRA spacecraft, launched in December 1999, travels in a near circular, sun-synchronous orbit with an inclination of approximately $98.2^{\circ}$, an altitude of $705 \mathrm{~km}$ and a repeat cycle of 16 days. The ASTER onboard the earth observing system (EOS) TERRA platform is a multispectral imaging system.

ASTER measures visible reflected radiation in three spectral bands (VNIR between 0.52 and $0.86 \mu \mathrm{m}$, with 15-m spatial resolution) and infrared reflected radiation in six spectral bands (SWIR between 1.6 and $2.43 \mu \mathrm{m}$, with $30-\mathrm{m}$ spatial resolution). In addition, ASTER records the data in band 3B (0.76-0.86 $\mu \mathrm{m})$ with a backward looking that enables the calculation of digital elevation model (DEM). Moreover ASTER receives emitted radiation in five spectral bands (TIR between 8.125 and $11.65 \mu \mathrm{m}$, with 90-m spatial resolution) (Fujisada, 1995). The purpose of the ASTER project is to understand local and regional phenomena on the Earth surface and its atmosphere. The VNIR region provides information about the presence of vegetation (Knipling, 1970), iron oxides (hematite, goethite, jarosite) and REEs (Hunt, 1977). The SWIR wavelength region assesses OH bearing minerals (clays, phyllosilicates) (Hunt, 1979) and the TIR wavelength region permits to distinguish silicates and carbonates (Salisbury et al., 1987). An increasing number of bands in the SWIR region enhance the surface lithological mapping capability. The surface temperature and emissivity can be calculated by the five spectral bands in the TIR region. Different standard data products obtained from ASTER system are land surface temperature, emissivity, reflectance and elevation maps (Gomez et al., 2005).

An improved geological map using ASTER data has been generated (Hewson et al., 2002) to understand the ability of ASTER data in delineation of regolith and alteration area in Australia. The band ratio and spectral unmixing techniques applied to SWIR, TIR and Emissivity data have improved the mapping of sedimentary, meta-sedimentary and volcanic areas. Cudahy and Hewson (2002) have distinguished some minerals in epithermal, porphyry and skarn groups through band ratio technique applied to ASTER bands. The ASTER data are utilized for lithologic discrimination to the Neoproterozoic basement rocks of Arafat area, Makkah Al-Mukarama, Western Arabian Shield, Saudi Arabia. Qari et al (2008) have utilized the ASTER data for lithologic discrimination of the basement rocks exposed over Arafat area, Western Arabian Shield, Saudi Arabia and generated 1:100,000 geological map using $6 / 8,4 / 8$, and $11 / 14$ band ratio images.

In this study, an attempt has been made to utilize Advanced Space borne Thermal Emission and Reflection radiometer short-wave infrared (ASTER SWIR) images for lithologic discrimination and mapping the late Archaean ultramafic layered igneous rocks. Anbazhagan and Arivazhagan, (2010) measured reflectance spectra of Sittampundi anorthosites, which is considered as equivalent (simulant) of lunar highland anorthosites. Anbazhagan et al., (2012) processed the Landsat ETM satellite data for the Sittampundi Anorthositic Complex and observed the low resolution remote sensing image characteristics of the anorthosites and surrounded rocks through spectral reflectance.

\section{Geological Setting of the Sittampundi Anorthositic Complex (SAC)}

The Neoarchaean Sittampundi anorthosite, situated in Namakkal District, in the state of Tamil Nadu, Southern India (Bhaskar Rao et al., 1996) is a metamorphosed anorthositic complex, preserving an original igneous stratigraphy overprinted by high-grade metamorphic assemblages (Subramaniam, 1956; Janardhanan and Leake, 1975; Windley and Selvan, 1975; Windley et al., 1981). The Geology of SAC has been extensively studied by Subramanian (1956); Ramadurai et al (1975); Janardhanan and Leake (1975). Iyer (1933) described the mafic granulites of the area as the early differentiates of the magma parental to the felsic granulites, mostly anorthosites as a first report of granulites in the Sittampundi area. Subramaniam (1956) described Sittampundi anorthositic complex as a metamorphosed layered igneous complex whereas Naidu (1963) and prior to that Nehru (1955) opined that the anorthositegneiss as originating from marly and pelitic sediments. However, later workers have recognized and emphasized the Sittampundi Complex as an Archean layered anorthositic igneous complex (Windley and Selvan, 1975; Ramadurai et al., 1975; Janardhanan and Leake, 1975). Sittampundi complex exposed 
over a strike length of about $20-25 \mathrm{~km}$, multiple folded and deformed structure. It is bounded by quartzo feldspathic hornblende-biotite gneiss which contains marbles, quartzite, and banded iron formations (Ramadurai et al., 1975). The Geological map of the Sittampundi Anorthosite Complex is shown in Figure 1.

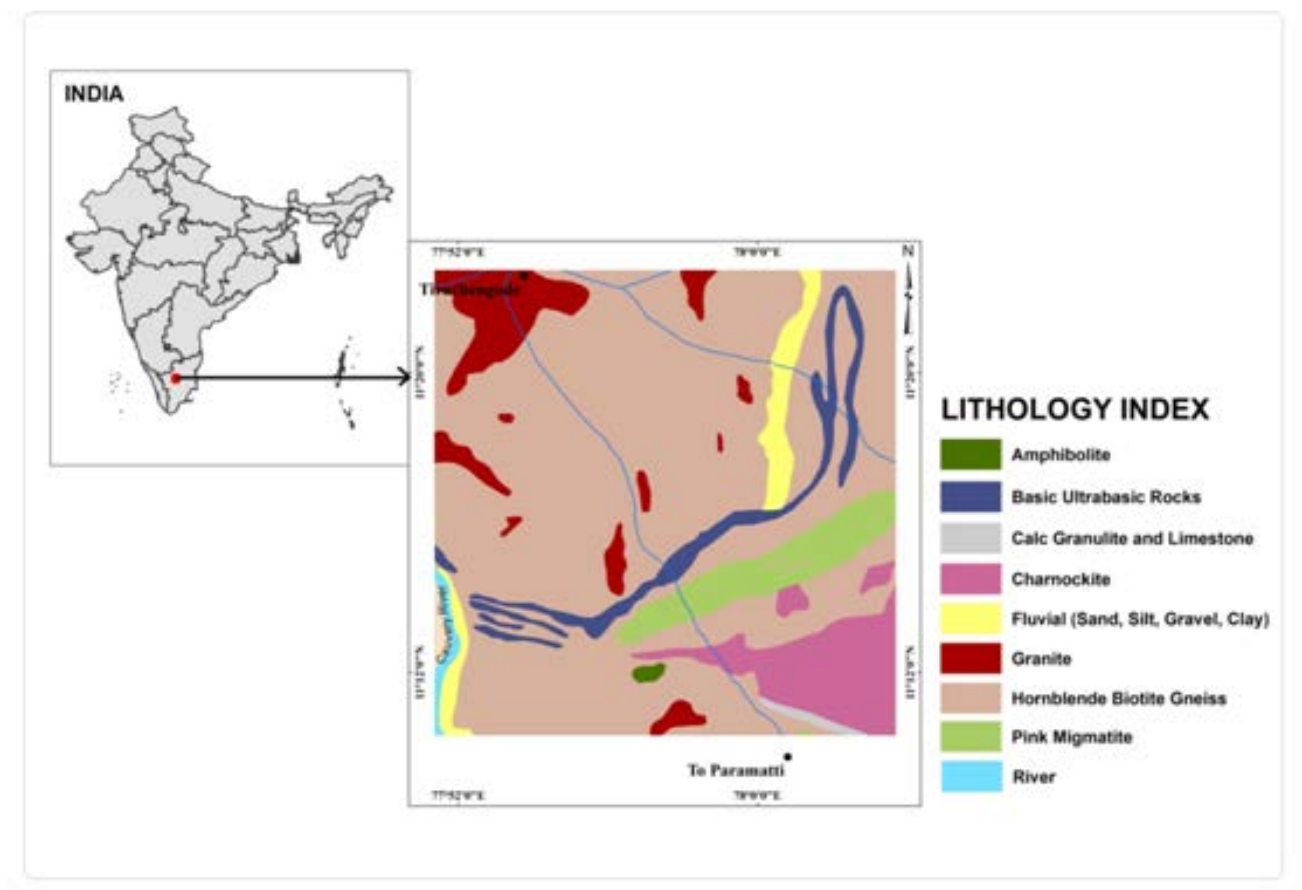

Figure 1. The location and Geology map of the Sittampundi Anorthosite Complex.

\section{Methodology}

The purpose of ASTER data analysis is to map different rock types in the study area to understand the ASTER data image characteristics and spectral signatures of the anorthosites and surrounding rock types. The study involves, collection of field samples to obtain laboratory spectral reflectance data, image processing of ASTER data and comparison of reflectance spectra of ASTER data with lab spectra and lunar anorthosites spectra. The potential of VNIR and SWIR ASTER data in lithological discrimination is understood through these studies. The regional geological map published by Geological Society of India (2005) is used as supporting map for the classification of ASTER images along with the reflectance spectra. The first step involved pre-processing of ASTER images such as cross talk correction and radiance to reflectance conversion of VNIR and SWIR 9 band ASTER data. In a second stage, Principal Component Analysis (PCA) is applied to all 9 ASTER bands. From PCA output composite image is developed for better discrimination of different rock types in the study area. The potentiality of VNIR, and SWIR ASTER data for geological applications has been explored for Sittampundi Anorthositic Complex. The image derived spectra are used as endmembers to classify the image through Spectral Angle Mapping (SAM) technique. The similar methodology can be adopted to other terrestrial and planetary mapping including image processing techniques along with the characterization of reflectance spectral features such as absorption, spectral pattern, percentage of reflectance, band width and band depth.

\section{ASTER Data Acquisition and Pre-Processing}

The Advanced Spaceborne Thermal Emission and Reflection radiometer (ASTER) onboard the Earth Observing System (EOS) TERRA platform is a multispectral imaging system. ASTER has three sensors to measure and record the reflected and emitted Electromagnetic Radiation (EMR). The VNIR, SWIR 
and TIR wavelength regions provide complementary data for lithological mapping. Each ASTER scene covers an area of $60 \times 60 \mathrm{~km}$ swath width. It is one of the five sensors on the TERRA satellite and is designed to acquire repetitive, high spatial resolution and multi spectral data from VNIR to TIR region for the first time from the commercial satellite. The specification of the ASTER data is given in Table 1.

Data Granule_Id = "ASTL1B 0301290523441202100006 (path 143 and row 052), acquired in December 2003 was used in the present study. Level 1B products contain radiometrically calibrated and geometrically co-registered data for all ASTER channels. These products were created by applying the radiometric and geometric coefficients to the Level 1A data. The level 1B radiances are generated at $15 \mathrm{~m}, 30 \mathrm{~m}$ and $90 \mathrm{~m}$ resolutions corresponding to the VNIR, SWIR and TIR channels respectively. (http://www.science.aster.erdac.or.jp/en/about_aster/sensor/tokutyou.html).

The use of ASTER data in mineral prospecting has increased in recent years because of its relatively low cost, broad coverage and unique integral bands highly sensitive to alteration minerals. The proper preprocessing and combination of ASTER bands can produce relative mineral alteration distribution maps such as iron oxides, siliceous rocks, carbonates, sericite, illite, alunite, and kaolinite. Some of the spectral bands of ASTER data are found to be sensitive for clays and iron absorptions. The seven extra bands of ASTER over the Landsat instrument, allow an increased diversity of processing techniques that can be performed. The increased spectral resolution allows spectral angle mapping and unmixing processing, similar to that performed on hyperspectral images, as well as a greater number of band ratios. The higher number of spectral bands enables band ratios to discriminate mineral groups, such as $\mathrm{Al}-\mathrm{OH}$ or $\mathrm{Mg}-\mathrm{OH}$, rather than the broad categories of materials that can be differentiated by Landsat TM. Although the limited number of bands does not allow the identification of specific minerals, the unmixing process has been proven to be able to identify abundances of mineral groups (Hewson et al., 2001). ASTER band ratios image (4/7, 4/6, 4/10) was used by Gad and Kusky (2006) for mapping the granite and metamorphic belt of the Wadi Kid area of Sinai, Egypt and concluded that, these band ratios can be used for mapping metamorphic rocks in the Arabian Nubian Shield and other arid regions. This study aims to develop appropriate methods for using ASTER data in using Principal Component Analysis (PCA), different band combinations and band ratios to understand the lithology of Sittampundi Anorthosite Complex.

ASTER standard data products are available through 'on-demand' from the Earth Remote Sensing Data Analysis Center (ERSDAC; Japan) and the EROS data center (EDC; USA). Basically, all the ASTER captured data are processed to generate Level-1A data product, which consists of unprocessed raw image data and coefficients for radiometric correction. The Level-1B (radiance-at-sensor) data product is a re-sampled image data generated from the Level-1A data by applying the radiometric and geometric correction coefficients (Abrams et al., 2004). Level-2 data products of measured physical parameters include: surface radiance data with nominal atmospheric corrections (Level- 2B01), surface reflectance data contains atmospherically corrected VNIR-SWIR data (Level-2B07 or AST-07), surface emissivity data with MODTRAN atmospheric correction and a temperature-emissivity separation (TES) algorithm (Level-2B04), which are all generated based on user request (Gillespie et al., 1998; Thome et al., 1998; Yamaguchi et al., 1999). Level-4B data product is also generated under the user request from the along-track stereo observation in the near infrared channel (band $3 \mathrm{~N}$ and $3 \mathrm{~B}$ ) in order to construct Digital Elevation Models (DEMs). Level-3A is a geometrically well-corrected orthorectified ASTER standard data product with ASTER-driven DEM, which is radiometrically equivalent to Level-1B radiance-at-sensor data (Abrams, 2000; Ninomiya et al., 2005; Yamaguchi et al., 2001). During scene acquisition of ASTER data, there is optical 'crosstalk' effect caused by stray of light from band 4 detector into adjacent band 5 and 9 detectors on SWIR subsystem (Iwasaki and Tonooka, 2005). Such deviations from correct reflectance result in false absorption features and distortion of diagnostic signatures which result in spectroscopic misidentification of minerals (Mars and Rowan, 2010). The 'crosstalk' effect caused by stray of light from band 4 detector into adjacent band 5 and 9 detectors on SWIR subsystem was corrected using 'crosstalk correction programme' which is available at www.gds.aster.ersdac.

The reflectance is an intrinsic property of materials, independent from illumination conditions, slope, sensor and atmospheric effects. The reflectance has been extracted from the digital number (DN) for the VNIR and SWIR spectral ranges. Preprocessing of the raw ASTER image involves calibration to ground-level reflectance, mapping and ortho-rectification using a digital elevation model. Here, we 
converted the ASTER L1B radiance at sensor data to TOA reflectance for minimizing the atmospheric effect. RTOA is calculated using the standard Landsat equation of

$$
\text { RTOA } \left.=\left(\text { mLrad } \mathrm{d}^{*} 2\right) / \text { ESUNi } \cos \mathrm{z}()\right)
$$

where, $\boldsymbol{\Pi}(\mathrm{pi})=3.14159$, RTOA is the planetary reflectance, Lrad is the spectral radiance at the sensor's aperture, ESUNi is the mean solar exoatmospheric irradiance of each band $\mathrm{i}, \mathrm{z}$ is the solar zenith angle (zenith angle $=90$ - solar elevation angle), which is within the ASTER header file, and d is the earthsun distance, in astronomical units.

$$
\mathrm{d}=(1-0.01672 * \operatorname{COS}(\operatorname{RADIANS}(0.9856 *(\text { Julian Day }-4))))
$$

LIB data processed into calibrated radiance at the sensor $(\mathrm{W} / \mathrm{m} 2 / \mathrm{sr} / \mu \mathrm{m})$ and unit conversion coefficient applied. The calculation of ESUNi is the same for whatever sensor we are using; as it is simply the convolution of the band's spectral response function (A) with the Extraterrestrial Solar Spectral Irradiance function (B). Using this standard approach the calculated ESUNi for each ASTER band is given in Table 1. In this study, we have used ESUNi data for the ASTER VIS-NIR bands given by Thome et al (1998).

\begin{tabular}{|c|c|c|c|c|c|}
\hline Subsystem & $\begin{array}{l}\text { Band } \\
\text { No }\end{array}$ & $\begin{array}{l}\text { Spectral range } \\
(\mu \mathrm{m})\end{array}$ & $\begin{array}{l}\text { ESUNi } \\
\text { Thome et al } \\
\text { (1998) }\end{array}$ & $\begin{array}{l}\text { Spatial Resolution. } \\
\text { m }\end{array}$ & $\begin{array}{l}\text { Quantization } \\
\text { levels }\end{array}$ \\
\hline \multirow{4}{*}{ VNIR } & 1 & $0.52-0.60$ & 1845.99 & \multirow{4}{*}{15} & \multirow{4}{*}{8 bits } \\
\hline & 2 & $0.63-0.69$ & 1555.74 & & \\
\hline & $3 \mathrm{~N}$ & $0.78-0.86$ & 1119.47 & & \\
\hline & $3 \mathrm{~B}$ & $0.78-0.86$ & & & \\
\hline \multirow{6}{*}{ SWIR } & 4 & $1.60-1.70$ & 231.25 & \multirow{6}{*}{30} & \multirow{6}{*}{8 bits } \\
\hline & 5 & $2.145-2.185$ & 79.81 & & \\
\hline & 6 & $2.185-2.225$ & 74.99 & & \\
\hline & 7 & $2.235-2.285$ & 68.66 & & \\
\hline & 8 & $2.295-2.365$ & 59.74 & & \\
\hline & 9 & $2.360-2.430$ & 56.92 & & \\
\hline \multirow{5}{*}{ TIR } & 10 & $8.125-8.475$ & & \multirow{5}{*}{90} & \multirow{5}{*}{12 bits } \\
\hline & 11 & $8.475-8.825$ & & & \\
\hline & 12 & $8.925-9.275$ & & & \\
\hline & 13 & $10.25-10.95$ & & & \\
\hline & 14 & $10.95-11.65$ & & & \\
\hline
\end{tabular}

Table 1. ASTER spectral and spatial resolution along with ESNUi data for VIS-SWIR regions

In the present study, we have processed VNIR and SWIR 9 bands to discriminate the different lithological units of the Sittampundi Anorthosite complex. In the next phase of work, it is planned to collect the thermal emissivity of the Sittampundi Anorthosite Complex to compare with the ASTER thermal bands. The image processing techniques including stretching, band combinations, band ratioing and Principle Component Analysis are tried to get the enhanced images of Sittampundi Anorthositic Complex. In band combinations, False Colour Composite (FCC), True Colour Composite (TCC) and Pseudo Colour Composite, PCA and spectral profiling were generated from the contrast stretched images.

\section{$5 \quad$ Digital Image Processing of ASTER Data}

\subsection{Contrast Stretching and Band Combinations}

The process of reassigning a range of values to another range, usually according to a linear function is called 'Contrast stretching'. Contrast stretching is often used in displaying continuous raster layers, since the range of data file values is usually much narrower than the range of brightness values on the 
display device. It simply stretches the range between the lower and higher data file values, so that the contrast of displayed image is higher that is, lower data file values are displayed with the lowest brightness values and higher data file values are displayed with higher brightness values. There are different methods of contrast stretching like simple linear contrast stretching, multiple linear contrast stretching and histogram equalization stretching.

Spectral analysis exploits spectral properties of rocks in order to interpret lithological variations or rock alterations that are expressed as variations in colour intensity values within colour composite images. Display of False Colour Composite (FCC) image in a colour scheme that is well balanced among the display colours is known as contrast-enhanced False Colour Composite, which is meant to provide better overview of the area of investigation. From 14 bands ASTER data, there are about 364 colour combinations that can be derived. The range of image enhancement technique is broad but composite generation is one of the fundamental techniques commonly used. Similar to other optical satellite data, different band combinations of ASTER data were prepared for visual analysis. True colour composite image generated using the band 1,2,3 in red, green, blue filters and it has given contrast signature for anorthosite in mixture of yellow and white colour (Figure. 2a). TCC is one of the good combinations for anorthosite discrimination as it represents true colour of object as seen through naked eye. The band combination provides excellent output particularly for anorthosite complex. In addition to anorthosite, the other rock types such as pink migmatite and hornblende biotite gneiss are also distinguishable. In FCC, bands 3,2 \& 1 were assigned as Red, Green and Blue colours respectively. FCC appears similar to an IR photograph, where objects do not have the same colour or contrast as they would naturally appear (Figure. 2b). FCC is considered as one of the basic combinations useful to discriminate not only lithology, but also for mapping land use and land cover category.

Bands 5, 4 \& 2 were used to create Pseudo Colour Composite image (PCC). In PCC the colours do not reflect the feature in natural colours. This band combination did not give much clarity for demarcating lithological boundaries (Figure. 2c). In band combination of 2, 3, 1 in RGB filter anorthosite enhanced in purple tint colour (Figure. 2d) and it should be clear boundary for demarcation. Pink migmatite is moderately enhanced, however the boundary condition is obscure between hornblende biotite gneiss and granite. Out of various processed outputs, the TCC $(1,2,3)$ and FCC $(3,2,1)$ band combinations have given better contrast for anorthosites, pink migmatite, hornblende-biotite gneiss and granite.

\subsection{Band Ratio}

Band ratio is an extremely useful procedure for enhancing features in multi spectral and hyperspectral images. Through band ratio technique, a specific element/mineral potential/abundance could be mapped based on the absorption feature characteristics of the respective minerals. The ratio images were prepared simply by dividing the DN values of each pixel in one band by DN values of another band (Drury, 1993). Image reflectance spectra used as reference to construct new ASTER band ratio image, where for each absorption feature, the numerator is the sum of the bands representing the shoulders and the denominator is the band located nearest the absorption feature minimum. The ASTER data of Sittampundi have shown the ferrous to ferric electron transition iron absorption features observed at $660 \mathrm{~nm}$ and 2160nm. Therefore ASTER band ratio was developed using the bands $1+3 / 2$ for $660 \mathrm{~nm}$ absorption band (Figure 3a) and $4+6 / 5$ for $2160 \mathrm{~nm}$ absorption band (Figure 3b). Density slice was applied to delineate the places where there is a high probability of occurrence of ferric iron. Hence, the blue colour region resembles with ferric iron in the images. Visual inspection of the SWIR band ratio image will reveal the most informative image for the discrimination and mapping of the different lithological unit in the Sittampundi Anorthositic Complex. The FCC developed with the ASTER ratio image of $\mathrm{R}(2 / 1), \mathrm{G}(6 / 7)$ and $\mathrm{B}(3 / 4)$ in RGB to map granites as shiny red to pink (Figure 3c) and ASTER ratio image of $\mathrm{R}(6 / 9), \mathrm{G}(4 / 6)$ and $\mathrm{B}(13 / 12)$ displayed as RGB, giving quartz as blue colour (Figure 3d). The rock also contains weathered plagioclase feldspar and it might be responsible for the $2220 \mathrm{~nm}$ absorption feature which is probably related to the Al-OH. 

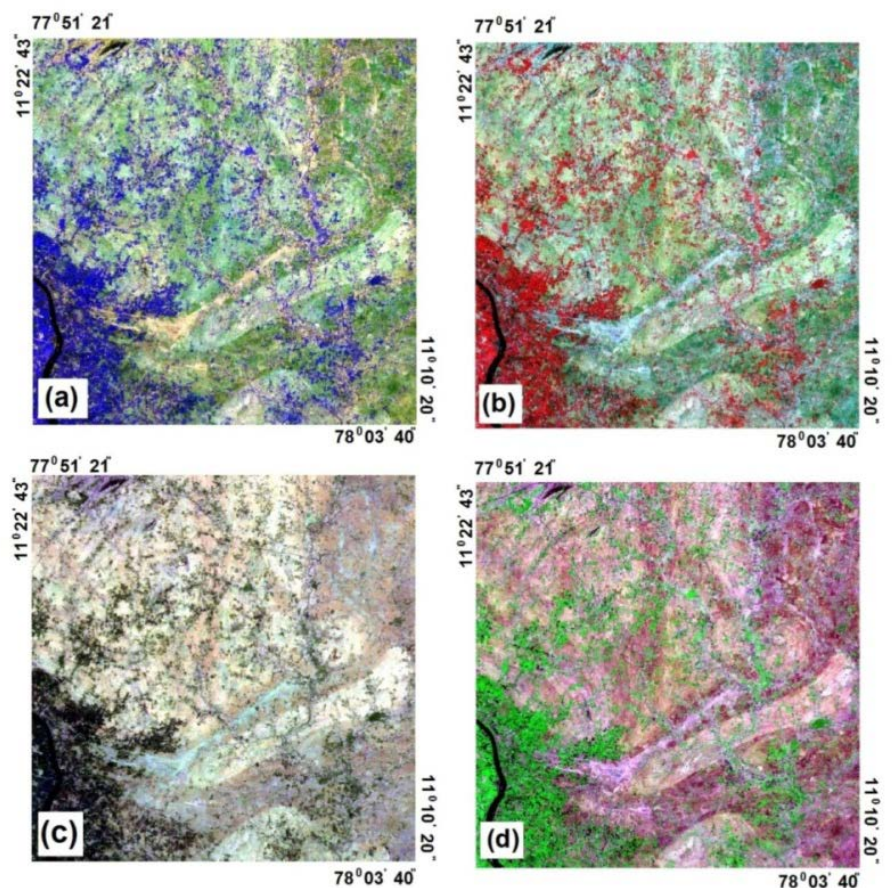

Figure 2. (a) True colour composite (TCC) image generated using the bands 1, 2, 3 assigned in red, green, blue filters. (b) False Colour Composite (FCC) image generated using 3, 2, 1 bands were assigned in Red, Green and Blue filters. (c) Pseudo Colour Composite image (PCC) with bands 5, 4, 2 assigned in Red, Green and Blue filters. (d) Band combination of 2, 3, 1 assigned in Green, Blue, Red filters.
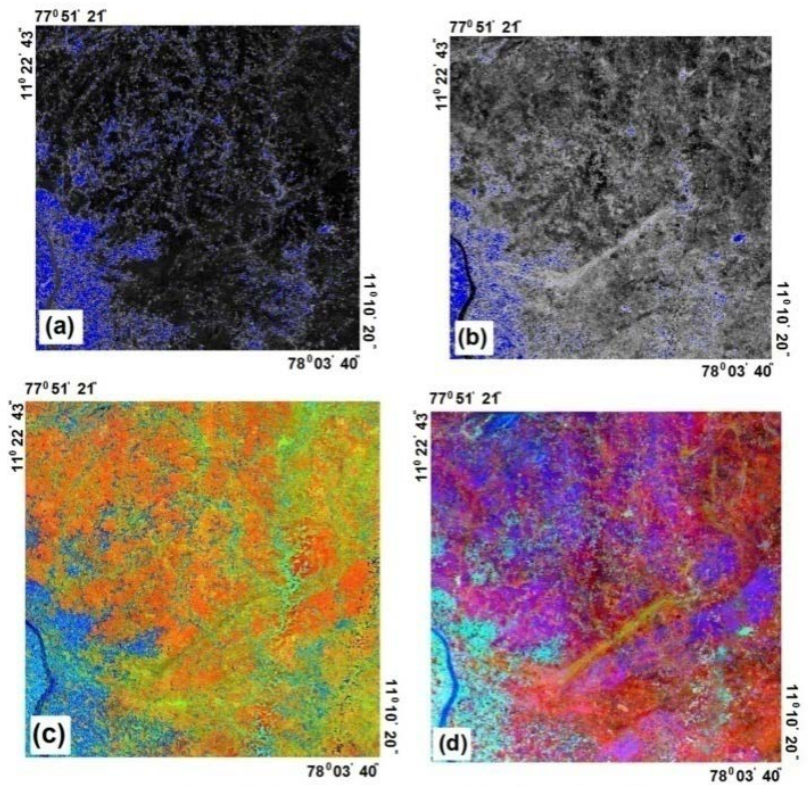

Figure 3. (a) Bands ratio of $(1+3 / 2)$ for the $660 \mathrm{~nm}$ absorption band. (b) Band ratio of $(4+6 / 5)$ for the $2160 \mathrm{~nm}$ absorption band. (c) The FCC developed with the ASTER ratio image of R (2/1), R (6/7) and R (3/4) displayed as RGB, giving granites as shiny red to pink. (d) The FCC developed with the ASTER ratio image of R (6/9), G (4/6) and B (13/12) displayed as RGB, giving quartz as blue colour. 


\subsection{Principal Component Analysis (PCA)}

The PCA is a multivariate statistical technique that selects uncorrelated linear combinations of variables in such a way that each component successfully extracts linear combination and has a smaller variance. PCA is a powerful technique for the analysis of correlated multidimensional data and its applications in digital remote sensing have been discussed by many workers (Kaneko, 1978; Byrne et al., 1980; Haralick and Fu, 1983). PCA increases overall separability and reduces dimensionality and is therefore highly useful in classification with same number of input and output spectral bands. The first PCA band contains the largest percentage of data variance and the second PCA band contains the second largest data variance whereas the last PCA bands appear noisy because they contain very little variance much of which is due to noise in the original spectral data (Sing and Harrison, 1985; Jensen, 2005; Chang et al., 2006). PCA is a well known method for lithological and alteration mapping in metalogenic provinces (Crosta et al., 2003; Kargi,2007; Massironi et al., 2008; Moore et al., 2008; Amer et al., 2010). In the present work, PCA analysis was performed to delineate the spectral variations in the subsetted image for further work including end member selection and classification through spectral angle mapping. Nine PCA outputs could be constructed from the original VNIR \& SWIR ASTER image data. Out of 9 outputs, the first six PCA images were chosen and considered as significant (Figure 4a). From PCA output, composite images were developed using band PC5, PC4 and PC2 for better discrimination between different rock types like anorthosites, amphibolites, charnockites, hornblende biotite gneiss, pink migmatite and granites. The resultant PCA image has been shown in Figure 4b. The PCA derived band combinations of True colour composite (PC1, PC2, PC3) and False Colour Composite (PC3, PC2, PC1) have also given much enhanced output and helped to demarcate the boundaries of anorthosites and other rock types.

(a)
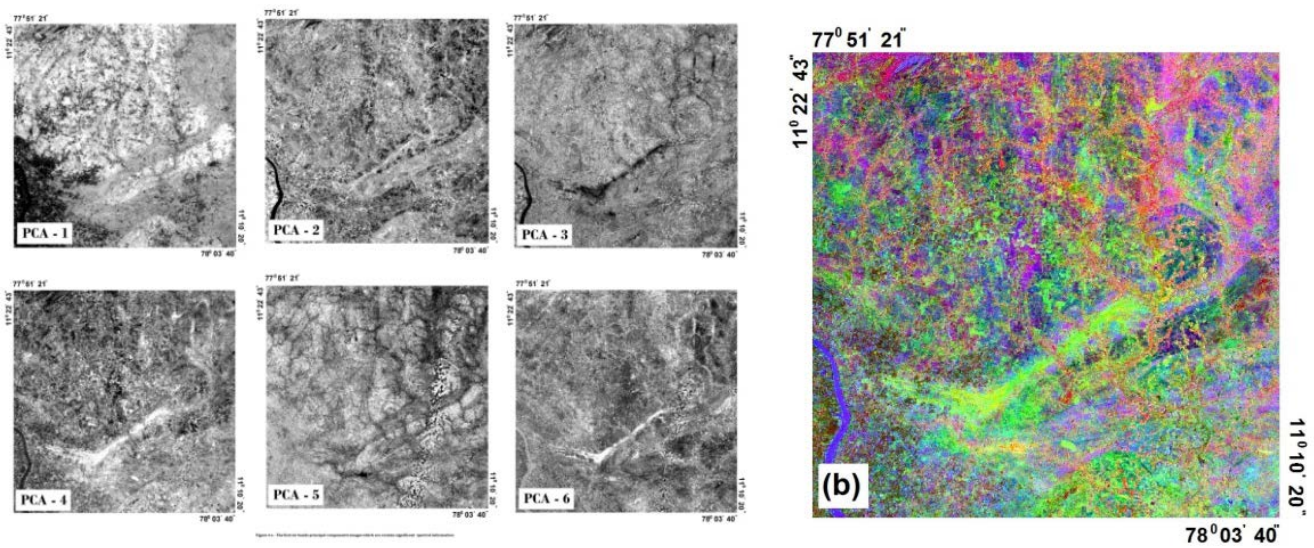

Figure 4. (a) The first six bands principal components images which are contain significant spectral information. (b) The PCA derived FCC (R-PC-5, G- PC-4 and B- PC2) for better discrimination of different rock types.

\subsection{Spectral Profiles and Matching}

The extracting pixel brightness values or the percentage of reflectance along with selected spatial profiles (transects) is often useful to extract the full spectrum of brightness values in ' $\mathrm{n}$ ' bands for an individual pixel. This is commonly referred to as a spectral profile. In a spectral profile, the $\mathrm{x}$-axis identifies the number of the individual bands in the dataset and the y-axis documents the brightness value (or percent reflectance) of the pixel under investigation for each of the bands (Jenson, 2005). The usefulness of spectral profile depends upon the quality of information in the spectral data. Spectral profile provides unique visual and qualitative information about the spectral characteristics of the phenomena under investigation (Jenson, 2005). The field reflectance spectra of anorthosites have shown weak absorptions at $650 \mathrm{~nm}, 750 \mathrm{~nm}$ and $950 \mathrm{~nm}$ (Arivazhagan et al. 2009). In Sittampundi anorthosite, the presence of ferrous iron in pyroxene may give rise to $\mathrm{Fe}^{2+}$ to $\mathrm{Fe}^{3+}$ intervalance charge transfer absorption bands near $650 \mathrm{~nm}$ and $750 \mathrm{~nm}$. The reflectance spectra do not show a prominent absorption features in these bands probably due to low $\mathrm{Fe}^{2+}$ to $\mathrm{Fe}^{3+}$ transition. The absorptions due to $\mathrm{Al}-\mathrm{OH}$ and 
$\mathrm{Mg}-\mathrm{OH}$ in terrestrial anorthosites show absorption doublets at $2200 \mathrm{~nm}$ and $2330 \mathrm{~nm}$ (Anbazhagan and Arivazhagan 2010), which may not be prominently shown in the lunar anorthosite spectra.

The spectral analysis has allowed us to discriminate the anorthosites and other rock types in the Sittampundi Anorthosite Complex. Spectral profiles generated from image and compared with laboratory spectra and spectral library. The spectral data extracted for VNIR and SWIR bands of ASTER satellite data. The contrast stretched spectral profile of nine band data is plotted for amphibolite, anorthosite, charnockite, hornblende biotite gneiss, pink migmatite, granite and vegetation in Figure 5a. Spectral profiles have been drawn based on the geology and PCA results in the Sittampundi Anorthosite Complex. The amphibolites and anorthosites have $34 \%$ of reflectance at 1660 $\mathrm{nm}$ and absorptions at $660 \mathrm{~nm}$ and $2160 \mathrm{~nm}$ due to ferrous to ferric electron transition. Charnockite and pink migmatite show maximum reflectance of $27 \%$ at $1660 \mathrm{~nm}$ and absorptions at $660 \mathrm{~nm}$ and $2160 \mathrm{~nm}$. Hornblende biotite gneiss and granite show similar spectral pattern and have maximum reflectance at 800-1660 $\mathrm{nm}$ and common absorptions at 660nm, however the second absorption differs in Hornblende biotite gneiss which has absorption at $2160 \mathrm{~nm}$ and granite which has absorption at $2220 \mathrm{~nm}$. The fluvial has maximum reflectance of $29 \%$ at $1660 \mathrm{~nm}$ region and absorption features at $660 \mathrm{~nm}, 2160 \mathrm{~nm}$ and $2260 \mathrm{~nm}$. The available John Hopkins University spectral library and laboratory derived reflectance data were resampled to the ASTER wavelengths and comparative spectral profiles were drawn to validate the ASTER data results. The three different spectral profiles have almost similar spectral pattern and common absorptions at $660 \mathrm{~nm}, 800 \mathrm{~nm}, 1660 \mathrm{~nm}, 2160 \mathrm{~nm}$ and $2220 \mathrm{~nm}$. The continuum removed laboratory spectra for different anorthosites collected from the study area are shown in Figure 5b. The spectral profiles of anorthosites, gabbro and norite are shown in Figure 5c from John Hopkins University Spectral library for the comparison of absorption features in the similar rock types. Further characterization including absorption pattern, band depth and strength of absorption bands from the hyperspectral image are required for micro level lithological discrimination of Sittampundi Anorthositic Complex.
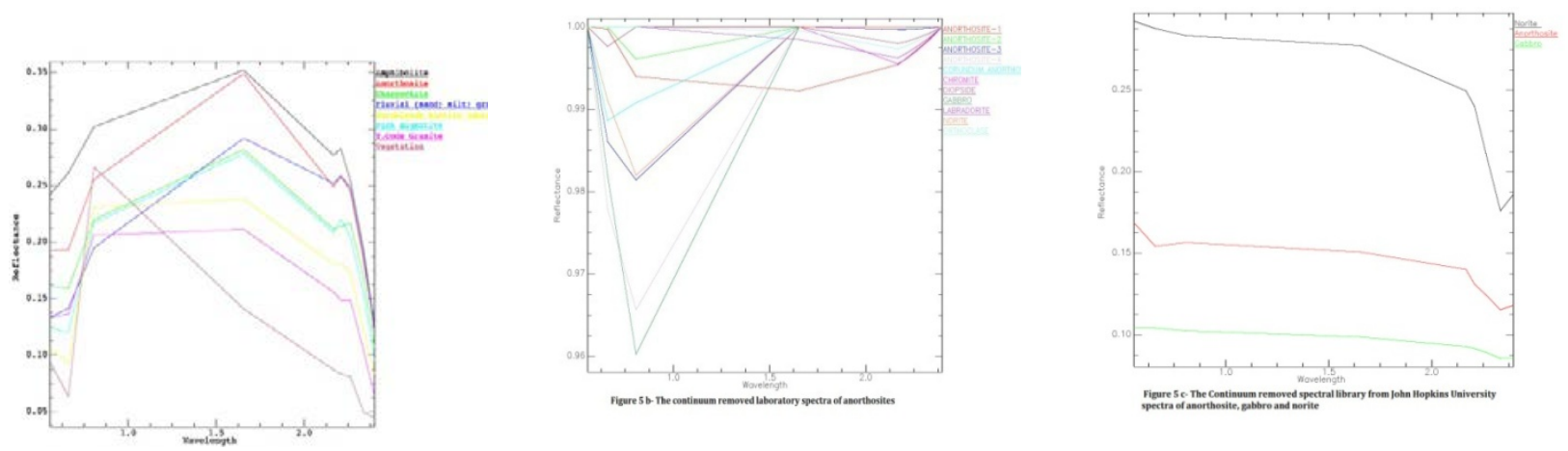

Figure 5. (a) The nine band data spectral profile is plotted for Amphibolite, Anorthosite, Charnockite, Fluvial, Hornblende Biotite gneiss, Pink migmatite, Granite, Vegetation and Fluvial region. (b) The continuum removed laboratory spectra of anorthosites. (c) The Continuum removed spectral library from John Hopkins University spectra of anorthosite, gabbro and norite.

\subsection{Spectral Angle Mapping (SAM)}

Spectral Angle Mapping is a physical-based spectral classification that uses an n-D angle to match pixels to reference spectra derived either from image, ground or laboratory. The algorithm determines the spectral similarity between two spectra by calculating the angle between the spectra and treating them as vectors in a space with dimensionality equal to the number of bands. This technique, when used on calibrated reflectance data, is relatively insensitive to illumination and albedo effects. SAM classification assumes, end member spectra used by SAM can come from ASCII files, spectral libraries, or spectra can be extracted directly from an image (as ROI average spectra). SAM compares the angle between the endmember spectrum vector and each pixel vector in n-D space. Smaller angles represent closer matches to the reference spectrum. Pixels further away than the specified maximum angle threshold are not classified by SAM algorithm (http://www.ittvis.com). In the present study, the spectral profiles for amphibolite, anorthosite, charnockite, hornblende biotite gneiss, pink migmatite, granite and vegetation 
were extracted and selected as end members and applied the SAM algorithm with ASTER images to map the Sittampundi Anorthosite Complex (Figure 6). In the Figures 5a and 6, the similar colours are used to demarcate the different lithologies in the study area.

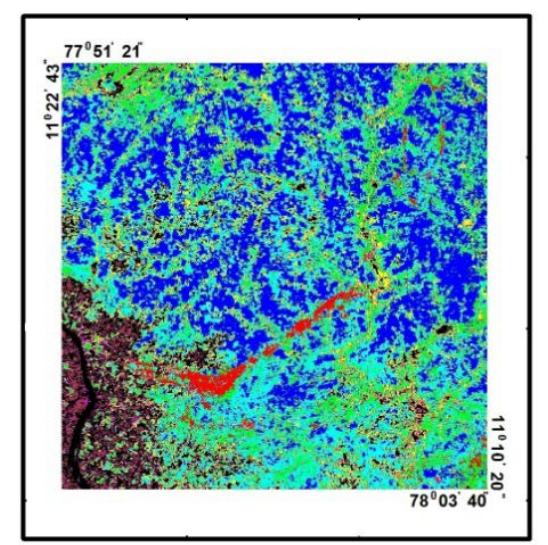

Figure 6. The Spectral Angle Mapping (SAM) showing different lithological boundaries. The different colours represent different lithologies similar to figure 5 a spectral curves.

\section{$6 \quad$ Results and Discussion}

Digital image processing of ASTER satellite data, TCC, band ratios and composite images of PCA outputs provided an enhanced output for SAC terrain. The spectral profile obtained from ASTER data enable researchers to interpret the absorption features and compare with spectral library and lunar rock spectra. The SAM has applied for extraction of end member spectra and plot the images for SAC region.

Sittampundi anorthosite is considered as a terrestrial equivalent to lunar anorthosite region and reflectance spectra captured under 350-2500 nm covering UV, Visible, NIR, and SWIR part of the electromagnetic spectrum (Anbazhagan and Arivazhagan, 2010). The spectral characteristics of anorthosites measured under various parts of electromagnetic spectrum have diagnostic absorption features at 380-390, 700-740, 930-1100, 1160-1200, 1415, 1920, 2200 and $2330 \mathrm{~nm}$ correspondingly due to plagioclase UV absorption, $\mathrm{Fe}^{3+}$ electron transition absorption, $\mathrm{Fe}^{2+}$ pyroxene and olivine absorption, $\mathrm{OH} / \mathrm{Mn}^{3+}$ crystal transition absorption, pyroxene absorption, $\mathrm{Al}-\mathrm{OH}$ absorption and $\mathrm{Mg}-\mathrm{OH}$ absorption (Arivazhagan et al., 2009; Anbazhagan and Arivazhagan, 2010). The occurrences and spatial distributions of anorthosites and other rocks can be identified, interpreted and mapped directly by visual interpretation over the RGB satellite images with various band combinations throughout the visible (400-700nm) and reflective infrared regions $(700-3000 \mathrm{~nm})$. The results obtained from the composite image of PCA are matched with the existing geological map of the Sittampundi Anorthositic Complex.

The spectral data for Apollo14 highland soils and Sittampundi anorthosites are obtained respectively from the RELAB and simulated environment in the Lab. The Apollo 14 highland soil spectra are plotted in the Figure 7. From these spectra, we observed ferrous electron transition absorption features at $660 \mathrm{~nm}, 800 \mathrm{~nm}, 2165 \mathrm{~nm}$ and $2200 \mathrm{~nm}$ are almost similar to Sittampundi anorthosite spectral features. Comparison of lunar and terrestrial anorthosite reflectance spectra has shown similar absorption features in the ASTER spectral resolution. The reflectance percentage of the terrestrial anorthosite derived from laboratory is slightly high, due to intensity of source light and variation in grain size. It should be characterized with respect to the chemistry, mineralogy, viewing angle, surrounding environment and source light used in the experiment. 


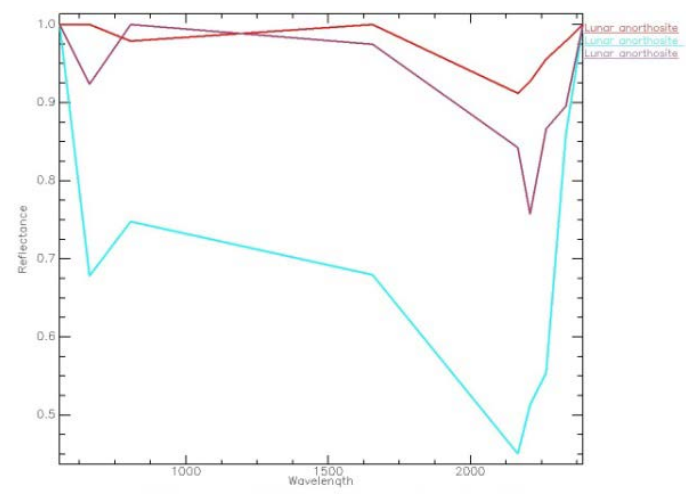

Figure 7. Reflectance spectra of Lunar anorthosites resampled to ASTER spectra.

On lunar surface, the iron bearing plagioclase has been identified using $1250 \mathrm{~nm}$ near infrared broad absorption due to electronic transitions of $\mathrm{Fe}^{2+}$. The laboratory studies of this near infrared feature have suggested that, band depth and band centre position at $1250 \mathrm{~nm}$ absorption may vary with Fe and An content respectively (Adams and McCord, 1971; Bell and Mao, 1973; Cheek et al., 2009). In the current scenario, the ASTER data do not have the bands at or near to $1250 \mathrm{~nm}$, so the $\mathrm{Fe}^{2+}$ plagioclase absorption could not be obtained in the present results.

\section{Conclusion}

This research would be useful in hyperspectral, mineralogical and petrological study of the SAC region. The feldspars are almost spectrally featureless except slight absorption features at $2145-2185 \mathrm{~nm}$ in ASTER band 6. Mapping of anorthosites and other rocks using the ASTER and library spectra facilitated the different types of mapping techniques include band combinations, band ratio, principal component analysis and spectral profiles substantially improved the existing knowledge of the geology of the area. This study concludes that usage of high spatial and spectral remote sensing techniques with field knowledge of the area significantly enhance the substantial information related to distribution of different lithology in the study area. However, the hyperspectral images with the high resolution like Hyperion and Hymap could be more accurate to delineate the lithological boundaries in the study area through spectral angle mapping and linear spectral unmixing techniques.

Comparison of laboratory spectra with image spectra shows appropriate matching in the absorption features. Further characterization including absorption pattern, band depth and strength of absorption bands along with insitu mineralogical and geochemical data are required to discriminate the micro level lithological classification of the Sittampundi Anorthositic Complex. ASTER VNIR data at $15 \mathrm{~m}$ resolution is currently the best resolution multispectral satellite data available commercially. However, the hyperpsectral data with less than 10nm spectral resolution may provide more information to develop the mineral and rock distribution maps in the study area.

Acknowledgement: The authors acknowledge the International Association of Mathematical Geology (IAMG) for student research grant and DST-SERB, New Delhi for Young Scientist research grant to carry out this research work.

\section{References}

1. J. B. Adams and T. B McCord,. Proceedings of the Apollo 12 Lunar Science Conference. Geochirn. Cosmochim. Acta. 3 (Suppl. 2), pp. 2183-2195, 1971.

2. M. J Abrams, D. Brown, L. Leply, R. Sadowski, Remote sensing for porphyry copper deposits in southern Arizona," Economic Geology, Vol. 78, pp. 591-604, 1983.

3. M. J. Abrams, and S. J. Hook, "Simulated ASTER data for geologic studies," IEEE Transactions of Geoscience and Remote Sensing, Vol. 33, pp. 692-699, 1955 
4. M . Abrams, "The Advanced Spaceborne Thermal Emission and Reflection Radiometer (ASTER): data products for the high spatial resolution imager on NASA's Terra platform," International Journal for Remote Sensing, Vol. 21 , pp. 847-859, 2000.

5. M. Abrams, S. Hook, B. Ramachandran, " ASTER User Handbook, Version 2. Jet Propulsion Laboratory, California Institute of Technology", 2004,

6. Online: http://asterweb.jpl.nasa.gov/content/03_data/04_Documents/aster_guide_v2.pdf2004.

7. R. Amer, T. Kusky, A. Ghulam, (2010), "Lithological mapping in the Central eastern Desert of Egypt using ASTER data," Journal of African Earth Sciences, Vol. 56, pp. 75-82, 2010.

8. S. Anbazhagan, and S. Arivazhagan, "Reflectance Spectra of analog Anorthosites; implications for lunar highland mapping," Planetary and Space Science, Elsevier, Vol. 58, pp. 752-760, 2010.

9. S. Anbazhagan, N. K. Sainaba, S. Arivazhagan, "Remote sensing study of Sittampundi, anorthosite complex, India," Indian Journal of Remote sensing, Springer, DOI 10.1007/s12524-011-0126, pp. 145-153, 2012.

10. S. Arivazhagan, Guru Balamurugan, K. N. Kusuma, and S. Anbazhagan, "Spectral reflectance studies of lunar analog rocks: In: S. Anbazhagan, R. Venkatachalapathy \& R. Neelakantan (Eds.)" Developments in exploration geology and geoinformatics, Macmillan India Ltd, pp. 245-254, 2009.

11. V. Balaram, R. Mathur, V. K. Banakar, J. R. Hein, C. R. M. Rao, T. G. Rao, and B. Dasaram,

"Determination of the platinum group elements (PGE) and gold (Au) in manganese nodule reference samples by nickel sulfide fire-assay and Te coprecipitation with ICP-MS," Indian Journal of Marine Sciences, Vol. 35, pp. 7$16,2006$.

12. P. M. Bell and H. K. Mao, "Optical and chemical analysis of iron in Luna 20 plagioclase," Geochimica et Cosmochimica Acta, Vol. 37, pp. 755-759, 1973.

13. Y. J. Bhaskar Rao, T. R. K. Chetty, A. S. Janardhan, K. Gopalan, "S.-Nd and Rb-Sr ages and P-T history of the Archean Sittampundi and Bhavani layered meta anorthosite complexes in Cauvery shear zone, South India: evidence for Neoproterozoic reworking of Archean crust," Contributions to Mineralogy and Petrology, Vol. 125, pp. 237-250, 1996.

14. G. F. Byrne, P. F. Crapper, and K. Mayo, "Monitoring land cover change by principle component analysis of multitemporal landsat data," Remote Sensing of Environment, Vol. 10, pp. 175-189, 1980.

15. Q. Chang, L. Jing, A. Panahi, "Principal Component analysis with optimum order sample correlation coefficient for image enhancement, International Journal for Remote Sensing, Vol. 27, pp. 3387-3401, 2006.

16. L. C. Cheek, C. M. Pieters, M. D. Dyar, and K. A. Milam, "Revisiting Plagioclase optical properties for Lunar Exploration," 40 $0^{\text {th }}$ Lunar and Planetary Science Conference, Vol. 1928, 2009.

17. A. P. Crosta, F. C. R. Souza, B. C. Azevedo, "Targeting key alteration minerals in epithermal deposits in Patagonia. Argentina, Using ASTER imagery and principal component analysis," International Journal for Remote Sensing, Vol. 24, pp. 4233-4240, 2003.

18. T. Cudahy, R. Hewson, "ASTER Geological Case Histories: Porphyry-Skarn-Epithermal, Iron Oxide $\mathrm{Cu}-\mathrm{Au}$ and Broken Hill Pb-Zn-Ag," Communication in the Workshop Mapping the Earth with ASTER, London, 2002.

19. P. A. Davis, and G. L. Berlin, "Rock Discrimination in the Complex Geologic Environment of Jabal Salma, Saudi Arabia, Using Landsat Thematic Mapper Data," Photogrammetric Engineering and Remote Sensing, Vol. 55, pp. 1147-1160, 1987.

20. S. A. Drury, Image Interpretation in Geology, 2nd edition, pp.283, 1993.

21. H. Fujisada, "Design and performance of ASTER instrument. Proceedings of SPIE," The International Society for Optical Engineering, Vol. 2583, pp. 16-25, 1995.

22. S. Gad, and T. Kusky, "ASTER Spectral Rationing for Lithological Mapping in the Arabian-Nubian Shield, the Neoproterozoic Wadi Kid Area, Sinai, Egypt," Gondwana Research, Vol. 11, pp. 326-335, 2007.

23. S. Gad, and T. M. Kusky, "Lithological mapping in the Eastern Desert of Egypt, the Barramiya area using Landsat thematic mapper (TM)," Journal of African Earth Sciences, Vol. 44, pp. 196-202, 2006.

24. B. Ghosh, and R. Konar, "Chromites from meta-anorthosites, Sittampundi layered igneous complex Tamil Nadu, Southern India," Journal of Asian Earth Sciences, Vol. 42, pp. 1394-1402, 2011.

25. A. R. Gillespie, T. Matsunaga, S. Rokugawa, S. J. Hook, "Temperature and emissivity separation from Advanced Spaceborne Thermal Emission and Reflection Radiometer (ASTER) images," IEEE Transactions of Geoscience and Remote Sensing Vol. 36, pp. 1113-1126, 1998. 
26. C. Gomez, C. Delacourt, P. Allemand, P. Ledru, R. Wackerle, "Using ASTER Remote Sensing Data Set for Geological Mapping, in Namibia," Physics and Chemistry of the Earth, Vol. 30, pp. 97-108, 2005.

27. R. M. Haralick, K. Fu, "Pattern recognition and classification. In: Colwell RN (ed) Manual of Remote sensing," Am Society of Photogrammetry and Remote Sensing, pp. 793-805, 1983.

28. R. D. Hewson, T. J. Cudahy, J. F. Huntington, "Geological and alteration mapping at Mt Fitton, South Australia, using ASTER satellite-borne data," IEEE Transactions of Geoscience and Remote Sensing, pp. 724-726, 2001.

29. R. Hewson, C. Koch, A. Buchanan, A. Sanders, "Detailed geological and regolith mapping in the Bangemall Basin, WA, using ASTER multi-spectral satellite-borne data. Communication in the Workshop Mapping the Earth with ASTER, London", 2002.

30. R. D. Hewson, T. J. Cudahy, S. Mizuhiko, K. Ueda, A. J. Mauger, "Seamless geological map generation using ASTER in the Broken Hill-Curnamona province of Australia," Remote Sensing of Environment, Vol. 99, pp. 159$172,2005$.

31. G. R. Hunt, "Spectral signatures of particulate minerals in the visible and near infrared" Geophysics Vol. 42, pp. 501-513, 1977.

32. G. R. Hunt, "Near infrared $(1.3-2.4 \mu \mathrm{m})$ spectra of alteration minerals-potential for use in remote sensing," Geophysics, Vol. 44, pp. 1974-1986, 1979.

33. A. Iwasaki, H. Tonooka, "Validation of a crosstalk correction algorithm for ASTER/ SWIR" IEEE Transactions of Geoscience and Remote Sensing, Vol. 43, pp. 2747-2751, 2005.

34. L. A. N. Iyer, "On the corundum-bearing rocks of Namakkal taluk, Salem district," Madras Presidency (Abstract). In: Proceeding Indian Science Congress, Vol. 20, 1933.

35. A. S. Janardhanan, and B. E. Leake, "The origin of the meta-anorthositic gabbros and garnetiferous granulites of the Sittampundi complex, Madras, India," Journal of Geological Society of India, Vol. 16, pp. 391- 408, 1975

36. J. R. Jensen, "Introductory Digital Image Processing," $3^{\text {rd }}$ edition, Pearson Prentice Hall, pp. 526, 2005.

37. T. Kaneko, "Colour composite pictures from principal axis components of multispectral scanner data," IBM Journal of Research and Development, Vol. 22, pp. 386-392, 1978.

38. H. Kargi, "Principal components analysis for borate mapping," International Journal for Remote Sensing, Vol. 28, No. 8, pp. 1805-1817, 2007.

39. E. B. Knipling, "Physical and physiological basis for the reflectance of visible and near-infrared radiation from vegetation," Remote Sensing of Environment, Vol. 1, pp. 155-159, 1970.

40. A. Madani, "Selection of the Optimum Landsat TM Bands for Lineament Extraction, Wadi Natash Area, South Eastern Desert, Egypt", Asian Journal of Geoinformatics, Vol. 3, No. 1, pp. 71-76, 2002.

41. J. C. Mars, L. C. Rowan, "Regional mapping of phyllic- and argillic-altered rocks in the Zagros magmatic arc, Iran, using ASTER data and logical operator algorithms," Geosphere, Vol. 2, No. 3, pp. 161-186, 2006.

42. J. C. Mars, L. C. Rowan, "Spectral assessment of new ASTER SWIR surface reflectance data products for spectroscopic mapping of rocks and minerals," Remote Sensing for Environment, Vol. 114, pp. 2011-2025, 2010.

43. M. Massironi, L. Bertoldi, P. Calafa, D. Visiona, A. Bistacchi, C. Giardino, B. A. Schiavo, "Interpretation and processing of ASTER data for geologic mapping and granitoids detection in the Saghro massif, "Geosphere, Vol. 4, No. 4, pp. 736-759, 2008.

44. F. Moore, F. Rastmanesh, H. Asady, S. Modabberi, "Mapping mineralogical alteration using principal component analysis and matched filter processing in Takab area, north-west iran, from ASTER data," International Journal for Remote Sensing, Vol. 29, No. 10, pp. 2851-2867, 2008.

45. P. R. J. Naidu, "A layered complex in Sittampundi, Madras state, India," Mineralogical Society of America Special paper, Vol. 1, pp. 116-123, 1963.

46. C. E. Nehru, "Geology and petro chemistry of the anorthosite gneiss and associated rocks of Sittampundi, Salem district," Journal of Madras University Vol. 25, 178-188, 1955.

47. Y. F. B. Ninomiya, and T. Cudahy, "Detecting Lithology with Advanced Spaceborne Thermal Emission and Reflection Radiometer (ASTER) Multispectral Thermal Infrared 'Radiance-at-Sensor' Data”, Remote Sensing of Environment, Vol. 99, No. 1-2, pp. 127-139, 2005.

48. S. Pena, and M. Abdelsalam, "Orbital Remote Sensing for Geological Mapping in Southern Tunisia: Implication for Oil and Gas Exploration," Journal of African Earth Sciences, Vol. 44, pp. 203-219, 2006. 
49. M. H. T. Qari, A. A. Madani, M. I. M. Matsah, and Z. Hamimi, "Utilization of ASTER and LANDSAT data in geologic mapping of basement rocks of Arafat area, Saudi Arabia," The Arabian Journal for Science and Engineering, Vol.33, No.1C, pp. 99-116, 2008.

50. F. Qiu, M. Abdelsalam, and P. Thakkar, "Spectral Analysis of ASTER Data Covering part of the Neoproterozoic Allaqi-Heiani Suture, Southern Egypt", Journal of African Earth Sciences, Vol. 44, pp. 169-180, 2006.

51. S. Ramadurai, M. Sankaran, T. A. Selvan, B. F. Windely, "The stratigraphy and structure of the Sittampundi complex, Tamil Nadu," Journal of Geological Society of India, Vol. 16, pp. 409-414, 1975.

52. L.C. Rowan, and J. C. Mars, "Lithologic mapping in the Mountain pass, California area using ASTER data," Remote Sensing of Environment, Vol. 84, No. 3, pp. 350-366, 2003.

53. L.C. Rowan, R. G. Schmidt, and J. C. Mars, 2006 "Distribution of Hydrothermally Altered Rocks in the Reko Diq, Pakistan Mineralized Area Based on Spectral Analysis of ASTER Data," Remote Sensing of Environment, Vol. 104, No. 1, pp. 74-87, 2006.

54. F. Sabins, "Remote Sensing Principles and Interpretation," $3^{\text {rd }}$ ed., pp. 494, 1997.

55. J. W. Salisbury, L. S. Walter, N. Vergo, "Mid-infrared (2.1-25 m) Spectra of Minerals, first ed." United States Geological Survey, Open File Report, pp. 87-263, 1987.

56. A. Singh, A. Harrison, "Standardized principal components," International Journal for Remote Sensing, Vol. 6, pp. 883-896, 1985.

57. A. P. Subramaniam, "Mineralogy and Petrology of the Sittampundi complex, Salem district, Madras State, India," Geological Society of America Bulletin, Vol. 67, pp. 317-390, 1956.

58. M. Sultan, R. E. Arvidson, N. C. Sturchio, and E. A. Guinness, "Lithologic Mapping in Arid Regions with Landsat Thematic Mapper Data, Meatiq Dome," Geological Society of America Bulletin Vol. 99, pp. 748-763, 1987.

59. K. Thome, F. Palluconi, T. Takashima, K. Masuda, "Atmospheric correction of ASTER. IEEE Transactions of Geosciences and Remote Sensing, Vol. 36, No. 4, pp. 1119-1211, 1998.

60. B. F. Windley, F. C. Bishop, J. V. Smith, "Metamorphosed layered igneous complexes in Archean granulitegneiss belts," Annual Review of Earth and Planetary Science, Vol. 9, pp. 175-198, 1981.

61. B. F. Windley, T. A. Selvan, "Anorthosites and associated rocks of Tamil Nadu, Southern India," Journal of Geological Society of India, Vol. 16, pp. 209-215, 1975.

62. Y. I. Yamaguchi, H. Fujisada, M. Kudoh, T. Kawakami, H. Tsu, A. B. Kahle, M. Pniel, "ASTER instrument characterization and operation scenario," Advanced Space Research, Vol. 23, No. 8, pp. 1415-1424, 1999.

63. Y. I. Yamaguchi, H. Fujisada, A. B. Kahle, H. Tsu, M. Kato, H. Watanabe, I. Sato, M. Kudoh, "ASTER instrument performance, operation status, and application to Earth sciences," IEEE Transactions of Geosciences and Remote Sensing, pp. 1215-1216, 2001. 